\title{
Replenishing the Spiritual Needs in Patients with Infaust Prognosis in Praguean and the Central Bohemian Region's Hospitals (Research Note)
}

D. R. Ralbovska (Dana Rebeka Ralbovska), M. Zavis (Monika Zavis)

University of Zilina, Faculty of Humanities, SK

Original Article

\section{E-mail address:}

0liliom0@gmail.com

\section{Reprint address:}

Monika Zavis

University of Zilina, Faculty of Humanities

Univerzitna 1

01026 Zilina

SK

Suource: Clinical Social Work and Health Intervention

Pages: $79-85$

Volume: 8

Cited references: 19

Issue: 4

\section{Reviewers:}

Vlastimil Kozon

Allgemeines Krankenhaus - Medizinischer Universitätscampus, Vienna, AT

Daniel J. West

University of Scranton, Department of Health Administration and Human Resources, USA

\section{Key words:}

Spirituality. Measuring Spirituality. Patients with Infaust Prognosis.

\section{Publisher:}

International Society of Applied Preventive Medicine i-gap

CSWHI 2017; 8(4): 79 - 85; DOI 10.22359/cswhi_8_4_10 @ 2017 Clinical Social Work and Health Intervention

\section{Abstract:}

Objective: The aim of our research was to determine the current situation at Praguean hospitals and hospitals of the Central Bohemia Region regarding the replenishing of spiritual needs in patients with infaust (unfavorable) prognosis.

Design: Pilot study. 
Participants: The criteria for selection of respondents were age (people over the age of 65), diagnosed with chronic disease with complications, infaust prognosis of their health condition and hospitalization in a healthcare facility in Prague and the Central Bohemia Region.

Methods: Investigation and evaluation of the current situation regarding this research problem was conducted using the FICA questionnaire, a tool of spiritual assessment that helps to discover personal spiritual history and provides guidelines for pastoral care in clinical practice. The research was conducted in hospitals in Prague and the Central Bohemia Region.

Results: During the research, we identified that the satisfaction of spiritual needs is at an insufficient level, and this deficit leads to a deterioration of the mental state of the patients.

Conclusion: In line with the research, the authors describe the appropriate forms of spiritual care that can be provided in the context of health care.

\section{Conflict of interest:}

The authors of this article certify that they have NO affiliations with or involvement in any organization or entity with any financial interest (such as honoraria; educational grants; participation in speakers' bureaus; membership, employment, consultancies, or other equity interest), or non-financial interest (such as personal or professional relationships, affiliations, knowledge or beliefs) in the subject matter or materials discussed in this manuscript.

\section{Introduction}

The multi-dimensional constitution of humans includes also spirituality. Replenishing their spiritual needs is at high demand in different kinds of personal struggles especially in patients with infaust prognosis. It is found, that many people experience spirituality as an important support aid while trying to cope with a chronic or life-threatening disease (1).

Palliative Medicine should not only be used to suppress physical pain, but also discomfort, anxiety, and other disease-related problems. Individually perceived loss of personal dignity; sense of life or hope can be reasons for giving up and the desire to die soon. Awareness of finitude; of one's mortality does not inevitably have to lead to minimization of the meaning of remaining

life. According to Baars, it relativizes cultural idols and poses the question of what life as a whole is really about (2). Ensuring the best possible quality of life for infaust patients is mainly helped by psychological, social and spiritual support (3). Keenan states, that by enhancing spiritual security, the professional can reduce the patient's/service user's spiritual vulnerability, risk and distress (4). Border issues in both Christian Pastoral Care and Clinical Psychology are concerned with in Pastoral Psychology (5).

The National Health Service Scotland has differentiated between spiritual care and religious care suggesting that, "spiritual care is usually given in a one to one relationship, is completely person-centered and makes no assumptions about personal conviction 
or life orientation"; it could be provided by all health care staff, by carers, families, and other patients. In contrast, "religious care is given in the context of shared religious beliefs, values, liturgies and life style of a faith community“"(6).

Academic Medical Centers, Medical and Nursing Schools, residency programs, and hospitals in the USA began to recognize the role of spiritual care as a dimension of palliative care in the early 1990s. Puchalski et al. came to a conclusion, that principles of spiritual care can be applicable across all phases and settings for seriously ill, without regard to culture, religious tradition, or spiritual frames of reference. They have defined spirituality as the aspect of humanity that refers to the way individuals seek and express meaning and purpose; the way they experience their connectedness to the moment, to self, to others, to nature, and to the significant or sacred. The most recognized models of spiritual care were considered as a bio-psycho-social-spiritual model of care and an inter-professional spiritual care model (7).

However, so far, attention for the spiritual needs of patients and dying in the Czech Republic has been implemented in health care facilities unsystematically and very diversely (8). In order to satisfy the spiritual care in the conditions of the Czech health care system, we refer to the Act on Health Services: Act No. 372/2011 Coll., where it is stated in detail that the patient is entitled in the provision of health services: "To receive spiritual care and spiritual support in medical facility at the patient department or daycare facilities from spiritual leaders of churches and religious societies registered in the Czech Republic or from persons charged with performing spiritual activities in accordance with the internal order and in a way that does not violate the rights of other patients and regarding their health status“ (9).
As we can see, there is no distinction between the spiritual and the religious care in Czech legislation, as mentioned above regarding Scotland.

\section{Patients and Methods}

Investigation and evaluation of the current situation regarding our research issue was made upon the questionnaire FICA, spiritual assessment tool developed by Dr. Christina Puchalski and a group of Primary Care Physicians. It helps to discover any personal spiritual history and the guidelines for the Pastoral Care in clinical praxis. The FICA questionnaire is the only validated screening questionnaire, which was also described in the Czech Republic. Health professionals can, using this tool deal with patients with spiritual issues that are important to them. According to the author of the Puchalski Questionnaire, the method of asking FICA questions is applicable across different cultures.

In all, 318 respondents aged 65 to 91 were involved in the survey. To comply with ethical considerations and to protect the rights of participants, the authors obtained permission; introduced themselves to participants; explained objectives of the study; obtained their informed consent; assured them of confidentiality of data; emphasized that they could withdraw from study as and when they wished. They were also assured that their names w not be disclosed.

\section{Results}

Based on this review of the literature, this paper addresses two research questions:

- Does infaust prognosis affect spiritual needs?

- Are the spiritual needs in hospitals sufficiently replenished? 
Question 1a: From the following variants of answers choose the one that characterizes your spirituality the most. Respondents could choose only one answer.

Table 1: Variants of answers regarding the spirituality of patients.

\begin{tabular}{|l|c|c|}
\hline variant of answer & $\mathbf{n}_{i}$ & $\mathbf{f}_{i}$ \\
\hline practicing believer & 120 & $37.7 \%$ \\
\hline believer & 82 & $25.8 \%$ \\
\hline atheist & 97 & $30.5 \%$ \\
\hline I do not want to answer & 19 & $6 \%$ \\
\hline Total & $\mathbf{3 1 8}$ & $\mathbf{1 0 0 \%}$ \\
\hline
\end{tabular}

Question 1b: In the case you have stated that you are a believer, did your infaust prognosis affect this fact? Respondents could choose only one answer.

The total number of respondents (based on the question number 1a) is 202 .

Table 2: Variants of answers on influence of infaust prognosis on spirituality of patients.

\begin{tabular}{|l|c|c|}
\hline variant of answer & $\mathbf{n}_{i}$ & $\mathbf{f}_{i}$ \\
\hline $\begin{array}{l}\text { I have been believer since } \\
\text { my childhood }\end{array}$ & 72 & $35.6 \%$ \\
\hline $\begin{array}{l}\text { my disease has brought me } \\
\text { faith }\end{array}$ & 94 & $46.5 \%$ \\
\hline $\begin{array}{l}\text { some other factors brought } \\
\text { me faith }\end{array}$ & 35 & $17.4 \%$ \\
\hline I do not want to answer & 1 & $0.5 \%$ \\
\hline Total & $\mathbf{2 0 2}$ & $\mathbf{1 0 0 \%}$ \\
\hline
\end{tabular}

Question 1c: In the case you have stated that you are an atheist, did your infaust prognosis affect this fact? The total number of respondents (based on the question number 1a) is 97 .
Table 3: Variants of answers on influence of infaust prognosis on their atheistic approach.

\begin{tabular}{|l|c|c|}
\hline variant of answer & $\mathbf{n}_{\mathbf{i}}$ & $\mathbf{f}_{\mathbf{i}}$ \\
\hline $\begin{array}{l}\text { I have an atheistic approach } \\
\text { since birth }\end{array}$ & 59 & $60.8 \%$ \\
\hline $\begin{array}{l}\text { I have an atheistic approach } \\
\text { based on the other factors }\end{array}$ & 15 & $15.5 \%$ \\
\hline $\begin{array}{l}\text { I have an atheistic approach } \\
\text { based on an infaust } \\
\text { prognosis }\end{array}$ & 14 & $14.4 \%$ \\
\hline I do not want to answer & 9 & $9.3 \%$ \\
\hline Total & $\mathbf{9 7}$ & $\mathbf{1 0 0 \%}$ \\
\hline
\end{tabular}

Question 2: What does the collocation of spiritual need mean to you? Respondents have chosen from the below-listed variants of responses (Table 4) all of those, which they consider important for the replenishing of their spiritual needs (they could have multiple answers).

Table 4: Variants of answers on comprehending the spiritual needs.

\begin{tabular}{|l|c|c|}
\hline variant of answer & $\mathbf{n}_{i}$ & $\mathbf{f}_{i}$ \\
\hline $\begin{array}{l}\text { interview with chaplain or } \\
\text { priest }\end{array}$ & 136 & $42.8 \%$ \\
\hline the need for faith & 172 & $54.1 \%$ \\
\hline securing the life safety & 144 & $45.3 \%$ \\
\hline $\begin{array}{l}\text { satisfaction of religious } \\
\text { needs }\end{array}$ & 64 & $83 \%$ \\
\hline $\begin{array}{l}\text { care for the soul and the } \\
\text { feelings }\end{array}$ & 86 & $58.5 \%$ \\
\hline the need for well-being & 259 & $81.4 \%$ \\
\hline the need for love & 32 & $73 \%$ \\
\hline the need for consolation & 25 & $39.3 \%$ \\
\hline reconciliation with death & 245 & $77 \%$ \\
\hline
\end{tabular}

Question 3: To what extent have you been satisfied with replenishing your spiritual needs during hospitalization at the health 
facility? Respondents have chosen from the following variants of responses (Table 5) the one that characterizes the most the degree of replenishing their spiritual needs during hospitalization (they could choose only one).

Table 5: Variants of respondents' answers regarding satisfaction with replenishing the spiritual needs in the health facility.

\begin{tabular}{|l|r|r|}
\hline variant of answer & $\mathbf{n}_{\mathbf{i}}$ & \multicolumn{1}{c|}{$\mathbf{f}_{\mathbf{i}}$} \\
\hline absolutely satisfied & 29 & $9.1 \%$ \\
\hline rather satisfied & 36 & $11.3 \%$ \\
\hline satisfied & 67 & $21 . \%$ \\
\hline rather dissatisfied & 39 & $12.2 \%$ \\
\hline dissatisfied & 45 & $14.2 \%$ \\
\hline $\begin{array}{l}\text { I did not feel the need } \\
\text { to replenish my spiritual } \\
\text { needs }\end{array}$ & 102 & $32.1 \%$ \\
\hline Total & $\mathbf{3 1 8}$ & $\mathbf{1 0 0 \%}$ \\
\hline
\end{tabular}

Evaluation of the first research question:

Does infaust prognosis affect spiritual needs?

On the basis of the results of our research, we can state that the influence of the infaust prognosis on the assumption of faith and spirituality was demonstrated in 94, ergo $\mathbf{4 6 . 5 \%}$ of the respondents (Table 2).

Evaluation of the second research question:

Are the spiritual needs in hospitals sufficiently replenished?

On the basis of the evaluation of the results of our research, we can state that of the 216 respondents (the total number of respondents was 318 and 102 of them did not have the need to replenish their spiritual needs that is to say 216), $132(61.1 \%)$ respondents were satisfied and $84(38.9 \%)$ of respondents were dissatisfied with replenishing their spiritual needs during hospitalization at the health care facility (Table 5).

\section{Discussion}

In this part of the article we will focus on comparing our findings with the results of other authors. We were wondering if an infaust prognosis had an impact on the development of spiritual needs. Our results affirm the results of the group of authors Samson et al. (2003). In the article titled, The experience of spirituality in hospitalized patients, they concluded that more than 93\% of patients with cancer believed spirituality helped them to strengthen their hope. Researchers emphasized the importance of the relationship with God as an aspect of spirituality that may provide some hope, optimism, and inner strength in adapting to stress (10). According to Samson et al. experiences of cancer patients also indicated that their transformation led to changes in their value system and priorities and they found a new perspective on life. All of these matters lead the individual to a position where life is meaningful and useful (11). The existence of a strong relationship between overall patient satisfaction and spiritual needs confirms the findings of the authors Ong et al. (12).

The authors Narayanasamy et al. dealt with the issue of satisfaction and the importance of spiritual needs. They reported correlation between the satisfaction of the spiritual needs and the satisfaction of the patient. In providing health care, they recommended interventions to meet the spiritual needs of the patient; including respect for privacy; helping patients connect with medical personnel; listening to their concerns; comforting and reassuring; using personal religious beliefs to assist patients; observation of their religious beliefs and practices (13).

Spirituality plays a significant role in the life of both the believer and the atheist. 
Especially in the occurrence of complications of chronical disease or infaust prognosis, the spiritual aspect of human personality is of great importance. Insufficient care for patients' spiritual needs may have a significant effect on the quality of life and well-being of the patient but may also cause a deterioration in overall health.

\section{Conclusion}

The results of this research study on a sample of 318 respondents (people over the age of 65), diagnosed with chronic complications or infaust prognosis clearly indicate that the following recommendations are needed to improve the state of care in the health care sector. These proposals mainly relate to attitudes of Doctors and General Nurses:

- Get acquainted with the Pastoral Care of the given hospital by healthcare professionals as part of the adaptation process.

- Inform patients (family) about the possibility of using spiritual services during reception and hospitalization.

- Create a unified recording system to identify the patient's spiritual needs in Nursing documentation.

- Establish the assessment of the patient's spiritual needs by an objective method - a questionnaire (for example FICA or HOPE).

- Improve communication between Medical Staff and Hospital Chaplains, and Pastoral Assistants.

It is also desirable to continue with a discussion of this issue.

\section{References}

1. STEFANEK M, MCDONALD P G, HESS S A (2005) Religion, Spirituality and Cancer: Current Status and Methodological Challenges. In Psycho-Oncology. 2005(14), pp. 450-463, doi: 10.1002/pon.861.
2. BAARS J (2010) Philosophy of Aging, Time, and Finitude. In A Guide to Humanistic Studies in Aging. ISBN 9780801894336 , pp. 105-120.

3. KUNG H (2015) Good Death? Praha 2015. ISBN 978-80-247-4659-3.

4. KEENAN P M (2017) Being and Feeling Spiritually Safe when Receiving Health and Social Care. In Catholic Medical Quarterly. Registered Charity Number 1002374, 67(2), pp. 1-3.

5. HOLM N G (1998) Introduction to Religion Psychology. Praha 1998. ISBN 8071782173.

6. JACKSON D, DOYLE C, CAPON H, PRINGLE E (2016) Spirituality, Spiritual Need, and Spiritual Care in Aged Care: What the Literature Says. In Journal of Religion, Spirituality \& Aging. ISSN 1552-8049, doi: 10.1080/15528030.2016.1193097.

7. PUCHALSKI CH, FERRELL B, VIRANI R, OTIS-GREEN SH, BAIRD P, BULL J, CHOCHINOV H, HANDZO G, NELSON-BECKER H, PRINCE-PAUL M, PUGLIESE K, SULMASY D (2009) Improving the Quality of Spiritual Care as a Dimension of Palliative Care: The Report of the Consensus Conference. In Journal of Palliative Medicine 12(10), 885-904, doi: 10.1089/jpm.2009.0142.

8. NOVOTNA H, KALA M (2015). Spiritual needs and their diagnosis in disease. In Palliative medicine and pain management. ISSN 1339-4193, 8(1), pp. 23-25 Law č.372 / 2011 Coll. Law about Health Services.

9. WONG KF, YAU SY (2010) Nurses' Experience in Spirituality and Spiritual Care in Hong Kong. In Applied Nursing Research 2010(23), pp.242-244, doi: 10.1016/j. apnr.2008.10.002.

10. SAMSONA, ZERTER B (2003) The Experience of Spirituality in the Psycho-social Adaptation of Cancer Survivors. In Journal of Pastoral Care \& Counsel 2003(57,) pp. 329343, doi: 10.1177/154230500305700308. 
11. RIDOSKO J (2014) Treatment of intra-articular femur fractures. Radix, spol. s. r. o. ISBN 978-80-87573-09-9.

12. ONG L M ET AL. (2000) Doctor-patient Communication and Cancer patients' Quality of Life and Satisfaction. Patient education and counseling 2000(41), pp. 145-156, doi: 10.1016/S0738- 3991(99)00108-1.

13. RIDOSKO J, STORCEL M (2013) Optimizing the treatment of heel bone fractures. 2. the results of the treatment. In Medical Horizon, ISSN 0457-4214. 2013, 62, 3, s. 95-101.

14. NARAYANASAMY A ET AL. (2004) Responses to the Spiritual Needs of Older People. Journal of Advanced Nursing 48 (1), pp. 6-16, doi: 10.1111 /j.13652648.2004.03163.x.

15. SISIKOVA A (2016) New possibilities in the treatment of chronic wounds. Treatment of chronic wounds with Granulox. In: Health and Social Work. ISSN 13336-9326. Vol. 11, No 4, p. 59-60.

16. RIDOSKO J (2012) Optimization of the treatment of bone fractures. In Medical Horizon. ISSN 0457-4214. 2012, 61, 6, s. 214-221.

17. BREZINOVA M (2015) Assessment of functional potential in patients after amputation of the lower limbs. In: Rehabilitation ISSN 0375-0922, Vol. 52, 2015, No 4, p. 218-226.

18. OLAH M (2016) Alternative child custody "Cochem's model". 1. ed. Nadlac: Editura Ivan Krasko, 2016. 221 pp. ISBN 9789731077060.

19. OLAH M, IGLIAROVA B (2015) Social services in legislation and practice. Bratislava: IRIS, 2015. 188 pp. ISBN 978-8089726-34-9. 